\title{
Vibrational Interaction of Two Rotors with Friction Coupling
}

\author{
H. Larsson and K. Farhang \\ Department of Mechanical Engineering and Energy Processes, Southern Illinois University Carbondale, Carbondale, IL 62901, USA
}

Correspondence should be addressed to K. Farhang; farhang@siu.edu

Received 1 May 2016; Accepted 30 August 2016

Academic Editor: Sven Johansson

Copyright (C) 2016 H. Larsson and K. Farhang. This is an open access article distributed under the Creative Commons Attribution License, which permits unrestricted use, distribution, and reproduction in any medium, provided the original work is properly cited.

\begin{abstract}
A lumped parameter model is presented for studying the dynamic interaction between two disks in relative rotational motion and in friction contact. The contact elastic and dissipative characteristics are represented by equivalent stiffness and damping coefficient in the axial as well as torsional direction. The formulation accounts for the coupling between the axial and angular motions by viewing the contact normal force a result of axial behavior of the system. The model is used to investigate stick-slip behavior of a two-disk friction system. In this effort the friction coefficient is represented as an exponentially decaying function of relative angular velocity, varying from its static value at zero relative velocity to its kinetic value at very high velocities. This investigation results in the establishment of critical curve defining two-parameter regions: one in which stick-slip occurs and that in which stick-slip does not occur. Moreover, the onset and termination of stick-slip, when it occurs, are related to the highest component frequency in the system. It is found that stick-slip starts at a period nearly equal to that of the highest component frequency and terminates at a period almost three times that of the highest component frequency.
\end{abstract}

\section{Introduction}

It has been known that mechanical systems with friction exhibit a phenomenon known as stick-slip. For example, in a brake system, a stator and a rotor in friction contact are in slip state initially at the start of braking. If the intent is to bring the rotor to a complete stop, then a permanent state of stick (zero relative velocity between the rotor and stator) will exist at the end of braking. In addition to the states of slip and stick, a stick-slip transition region may exist which is generally characterized by high frequency oscillations. In the stick-slip transition region, the system displays a series of transient states, that is, slip to stick, and vice versa. With progression of time, the states corresponding to stick gain increasingly larger duration up to the point at which a steady state of stick is achieved.

The existence of stick-slip gives rise to friction forces which are complex in nature and have been known to be responsible for adverse dynamic characteristics. The effects of stick-slip friction are manifested through the development of excessive vibration and noise. Friction-induced vibration is undesirable due to its detrimental effects on the operation and acceptable performance of mechanical systems. Frequent vibration leads to accelerated wear of components, surface damage, fatigue, and noise.

Many aspects of friction-induced vibration are found in the literature. For a comprehensive review of friction the reader may refer to Ibrahim $[1,2]$, Armstrong-Hélouvry et al. [3-6], Crolla and Lang [7], and Tabor [8]. Specifically, Oden and Martins [9] include a review on frictional contact of metallic surfaces and in a more recent publication by Martins et al. [10] some aspects of low speed frictional sliding phenomena are reviewed.

A simple system which has been used to examine the stick-slip phenomenon is that of a mass sliding on a moving belt [11, 12]. Another typical system is the pin-on-disk apparatus that has been utilized to study dynamic instabilities [13]. Analytical studies of a pin-on-disk apparatus [14] show that the coupling between rotational and normal modes of vibration is the primary mechanism of the resulting selfexited oscillations. Soom and Kim [15, 16] as well as Dweib and D'Souza [17] came to similar conclusions, showing that the force oscillations are primarily associated with the normal and tangential contact vibrations. This coupling effect was 
considered in the steady sliding point characterization of a simple system [18]. A dynamic stability study [19], considering the Schallamach waves (growing surface oscillations which propagate from front to rear at the friction surface), showed that, for large coefficients of friction and sufficiently large Poisson's ratio, steady sliding is unstable.

The most widely accepted cause of stick-slip motion is the speed dependence of kinetic friction [3, 4, 20-22]. The velocity term is often included in analytical models [5, 23]. Bengisu and Akay [24] modeled the friction force as an exponential function of the relative sliding velocity. The friction forces in a model of an automotive disk brake are defined in terms of relative sliding speed, pressure, and temperature at the friction interface [25]. Based on experimental data on stick-slip motion, Bo and Pavelescu [26] developed a friction model consisting of two exponential functions of relative speed. Linear stability theory has shown that there is a critical value of the normal load and the average coefficient of friction, above which the steady state sliding motion becomes unstable [27]. Similar results were found by [28] by studying the stability of a simple model where the friction force was assumed to be steady. It has been observed that the amplitude of the stick-slip motion decreases when the driving velocity, damping coefficient, and spring stiffness increase and the mass of the sliding body decreases [9]. Sherif and Kossa [29] measured and modeled the normal and tangential contact stiffness of two rough surfaces in contact. Sherif [30] analyzed the effect of contact stiffness on the instability condition of frictional vibration. Gao et al. [31] focus on the amplitude of stick-slip motion as a function of humidity, speed, and applied load. It is found that the stick-slip amplitude decreases with increasing substrate speed. In lubricated contacts, the cause of stick-slip motion is attributed to local region of instability where shear stress falls with respect to shear rate [32]. A set of lubricated contact experiments are presented by Polycarpou and Soom [33]. The transitions between sliding and sticking are measured and discussed.

In contrast to the speed dependence of the kinetic friction, Adams [34] presents a model for the dynamic interaction of two sliding surfaces, consisting of a series of moving linear springs at the friction interface. The springs are used to account for the elastic properties of asperities on one of the surfaces. The dynamic analysis indicates that the system is dynamically unstable for any finite speed, even though the coefficient of friction is constant. The idea of representing the friction interaction of two bodies using multiple elastic members such as springs or "bristles" is also presented by [35]. The authors assume that the friction between the two surfaces is caused by a large number of bristles, each contributing a small portion to the total load. The model is numerically inefficient and the authors therefore present a refined model.

In this paper a lumped parameter vibration model for a two-disk friction system is presented. A friction coefficient function that expresses the kinetic coefficient as a function of relative velocity is introduced. The interfacial force between the two plates is calculated based on the dynamic behavior of the disks in the axial direction. This is an important feature in that it allows direct coupling between the axial and rotational

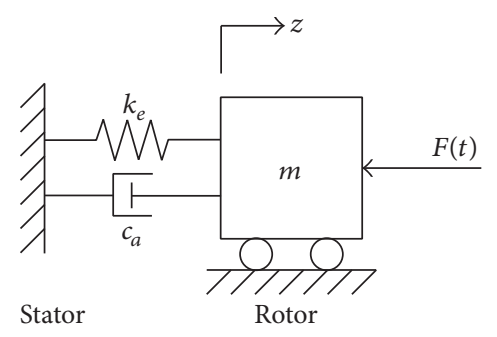

FIgURE 1: Schematic of the model in axial motion.

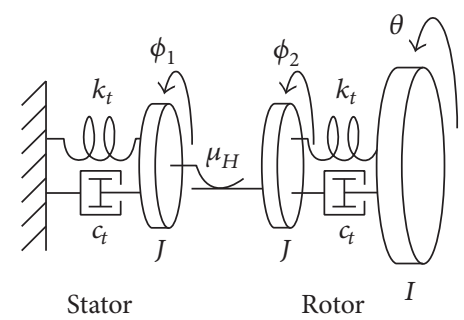

Figure 2: Schematic of the model in rotational sliding (slip) state.

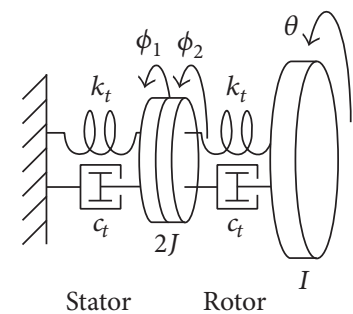

FIGURE 3: Schematic of the model in rotational stick state.

motions. That is, the rotational motion must be influenced by the actuating axial force and material properties of the friction material (stiffness and damping) in compression. Therefore, in addition to the properties of the friction material in torsional direction (shear), the model accounts for the properties in axial direction and how the combination of the mechanical properties can influence the dynamic behavior of the system. This capability enables simulations to accurately demonstrate effects of the mechanical properties on dynamic and vibration behavior of the friction system.

\section{The Two-Disk Model}

The interaction between two disks in frictional contact is represented using a lumped parameter model shown in Figures $1-3$. The two disks are engaged by the actuating force $F(t)$. The compression of the disks depends on $F(t), m$ (mass of the rotor), $k_{e}$ (equivalent axial stiffness of the disk pair), and $c_{a}$ (axial damping of the disk pair). The axial behavior of the disks determines the normal interface force between the disk surfaces. Figure 1 shows the schematic of the axial vibration model.

The differential equation of the axial motion for the system can be written as

$$
m \ddot{z}+c_{a} \dot{z}+k_{e} z=-F(t)
$$


The rotational motion of the system is modeled in two states, that is, sliding friction (slip state) and static friction (stick state). The schematics corresponding to the slip and stick states are shown in Figures 2 and 3, respectively. $J, k_{t}$, and $c_{t}$ are the lumped contact parameters (equivalent inertia, torsional stiffness, and damping coefficient) contributed by each disk. The friction torque at the surface depends on the two nonconstant variables: the normal interface force and the relative angular velocity.

We consider a situation in which the rotor, initially at a nonzero angular velocity, is brought to a complete stop by the application of an axial force and as a result of friction contact with the stator. The differential equation for the angular motion of the rotor can be written as

$$
I \ddot{\theta}+c_{t}\left(\dot{\theta}-\dot{\phi}_{2}\right)+k_{t}\left(\theta-\phi_{2}\right)=0 .
$$

The motion of the lumped inertia representing the contact will be governed by two sets of differential equations. When the two moments of inertia are in slip state,

$$
\begin{aligned}
J \ddot{\phi}_{2}-c_{t}\left(\dot{\theta}-\dot{\phi}_{2}\right)-k_{t}\left(\theta-\phi_{2}\right) & =-\mu_{H} r F_{n}, \\
J \ddot{\phi}_{1}+c_{t} \dot{\phi}_{1}+k_{t} \phi_{1} & =\mu_{H} r F_{n} .
\end{aligned}
$$

In stick state, the above reduces to a single differential equation

$$
\begin{aligned}
2 J \ddot{\phi}_{2} & =c_{t}\left(\dot{\theta}-\dot{\phi}_{2}\right)-c_{t} \dot{\phi}_{2}+k_{t}\left(\theta-\phi_{2}\right)-k_{t} \phi_{2}, \\
\phi_{1} & =\phi_{2} .
\end{aligned}
$$

The normal surface interface force depends on the axial motion as follows:

$$
F_{n}= \begin{cases}-c_{a} \dot{z}-k_{e} z, & -c_{a} \dot{z}-k_{e} z>0, \\ 0, & -c_{a} \dot{z}-k_{e} z<0 .\end{cases}
$$

The effective radius of tangential force $(r)$ can be estimated if the type of wear is known. Shigley and Mischke [36] show that, after the initial wear has taken place and the disks have worn down to the point where uniform wear is the governing mechanism, the following simple formula can be used to calculate $r$ :

$$
r=\frac{1}{4}(D+d),
$$

where $d$ and $D$ are the inner and outer diameters of the contact surface, respectively. When uniform pressure can be assumed over the area of the disk, the following formula may be used [36]:

$$
r=\frac{1}{3} \frac{\left(D^{3}-d^{3}\right)}{\left(D^{2}-d^{2}\right)}
$$

\section{Stick-Slip Friction}

A proposed friction coefficient function for the relative angular velocity $\omega_{r}$ is presented as follows:

$$
\mu_{H}=\operatorname{sgn}\left(\omega_{r}\right)\left(\mu_{d}+\left(\mu_{s}-\mu_{d}\right) e^{-\alpha\left|\omega_{r}\right|}\right)+\delta\left(\omega_{r}\right) \mu_{0},
$$

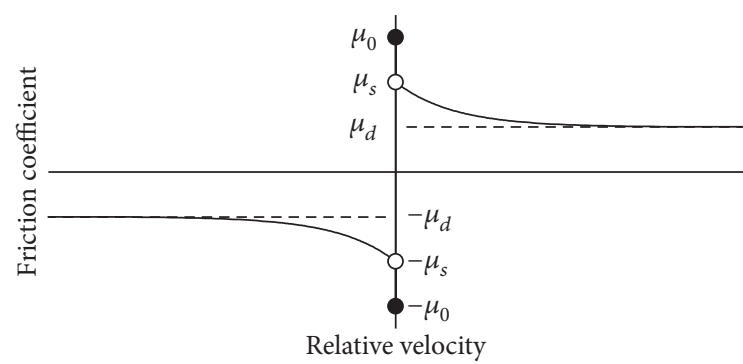

FIGURE 4: Proposed coefficient of friction function, $\mu_{H}$.

where $\delta$ is the Dirac delta function and the function parameters are defined as follows:

$$
\begin{aligned}
& \omega_{r}=\dot{\phi}_{2}-\dot{\phi}_{1} \text { is the relative angular surface velocity. } \\
& \mu_{s}=\mu\left(\omega_{r} \rightarrow 0^{+}\right) \text {is the friction coefficient for low } \omega_{r} . \\
& \mu_{d}=\mu\left(\omega_{r} \rightarrow \infty\right) \text { is the friction coefficient for high } \\
& \omega_{r} . \\
& \mu_{0}=\mu\left(\omega_{r}=0\right) \text { is the friction coefficient for zero } \omega_{r} . \\
& \alpha \text { is the friction coefficient decay rate. }
\end{aligned}
$$

Stick-slip motion is highly nonlinear behavior which occurs at the point where the relative velocity between the moving bodies is near zero. At zero relative velocity static friction dictates the behavior. This is a multivalued function implying that the friction force will take any value in the range of $-\mu_{0} F_{n}$ to $\mu_{0} F_{n}$ depending on the internal force within the material. As shown in Figure 4, the breakaway force can be larger than that corresponding to zero velocity. The magnitude of the external force must exceed the peak breakaway force $\left(\mu_{0} F_{n}\right)$ for sliding to occur. If $\mu_{d}$ is smaller than $\mu_{s}$, the coefficient of friction function has a negative slope. The negative slope acts as a nonlinear negative damper and may cause the system to enter a stick-slip phase.

Examination of the forces acting on the disks representing the surfaces $(J)$ suggests that, in order to have sliding contact, either the relative velocity $\left(\omega_{r}\right)$ must be other than zero or the internal force $\left(F_{i}\right)$ generated by spring and damper must exceed the friction force $\left(\mu_{0} F_{n}\right)$. Conversely, in order to have a stick contact, the relative velocity must be zero and the internal force must be less than the friction force. In general, it is very difficult to capture the instant at which relative velocity equals zero. For simulation purposes, the velocity condition may be written in terms of a tolerance, $\varepsilon$. This can be summarized as follows:

$$
\text { friction state }= \begin{cases}\text { slip, } & \text { if } F_{i}>\mu_{0} F_{n} \text { or }\left|\omega_{r}\right|>\varepsilon, \\ \text { stick, } & \text { if } F_{i} \leq \mu_{0} F_{n},\left|\omega_{r}\right| \leq \varepsilon\end{cases}
$$

where

$$
\begin{aligned}
& F_{i}=\frac{1}{r}\left|c_{t} \dot{\phi}_{1}+k_{t} \phi_{1}\right| \quad \text { stator surface, } \\
& F_{i}=\frac{1}{r}\left|c_{t}\left(\dot{\theta}-\dot{\phi}_{1}\right)+k_{t}\left(\theta-\phi_{1}\right)\right| \quad \text { rotor surface. }
\end{aligned}
$$




\section{Results}

4.1. Simulation Summary. In the simulations presented, the rotor is brought to a stop by the application of an axial actuating force. The axial force is assumed to increase linearly to a maximum value and to be kept constant thereafter.

$$
F(t)= \begin{cases}F_{0} \frac{t}{t_{0}}, & \text { if } t \leq t_{0} \\ F_{0}, & \text { if } t>t_{0}\end{cases}
$$

where $F_{0}$ and $t_{0}$ are the maximum axial actuating force and the application time, respectively. The rotor is assumed to rotate with an initial angular velocity $\omega_{0}$ at $t=0$, when the actuating force is applied. The object is to bring the rotor to a complete stop.

The parameters used in the simulations are as follows: equivalent axial stiffness, $k_{e}=55.38 \cdot 10^{6} \mathrm{~N} / \mathrm{m}$ (3.161 . $10^{5} \mathrm{lb} / \mathrm{in}$ ); axial damping, $c_{a}=8,760 \mathrm{~N} \mathrm{~s} / \mathrm{m}$ (50 lb-sec/in); disk mass, $m=4.54 \mathrm{~kg}(10 \mathrm{lbm})$; actuating force, $F_{0}=2,225 \mathrm{~N}$ $(500 \mathrm{lb})$; force application time, $t_{0}=1$ second; torsional stiffness, $k_{t}=7.71 \cdot 10^{6} \mathrm{Nm} / \mathrm{rad}\left(6.822 \cdot 10^{7} \mathrm{lb}-\mathrm{in} / \mathrm{rad}\right)$; torsional damping, $c_{t}=22.606 \mathrm{Nm} \mathrm{s} / \mathrm{rad}$ (200 lb-in-s/rad); effective radius of tangential force, $r=0.052388 \mathrm{~m}$ (2.0625 in); rotor inertia, $I=2.262 \mathrm{~kg} \mathrm{~m}^{2}$ (20 slug-in-ft); equivalent surface inertia, $J=0.0113 \mathrm{~kg} \mathrm{~m}^{2}$ (0.1 slug-in-ft); breakaway friction coefficient, $\mu_{0}=0.6$; friction coefficient for low velocities, $\mu_{s}=0.6$; friction coefficient for high velocities, $\mu_{d}=0.3$; relative angular velocity tolerance, $\varepsilon=0.00001$. Runge-Kutta 5 with step size from $10^{-8}$ to $10^{-4}$ and integration tolerance $10^{-11}$ is used. Before generating the final results, simulations were run at various accuracies by setting the step size. It was determined that the most appropriate settings for step size in the range involving smaller numbers (e.g., from $10^{-9}$ to $10^{-5}$ ) gave identical results to the ranges mentioned. Initial conditions at $t=0$ are $z=\dot{z}=0, \dot{\theta}=\dot{\phi}_{2}=100 \mathrm{rad} / \mathrm{s}$, and $\theta=\phi_{1}=\phi_{2}=\dot{\phi}_{1}=0$.

4.2. Time Response. Figure 5 illustrates the axial response of the system, resulting in rotor displacement of about $0.04 \mathrm{~mm}$. Figures 6 and 7 depict the rotor angular velocity. The closeup view in Figure 7 shows rotor velocity during a very small window of time of $(<0.04$ seconds $)$ that includes a small portion of slip state, all the stick-slip state, and a small portion of stick state. This is a decaying oscillation that eventually gets attenuated during the stick state of the system. The angular velocities of the rotor and stator surfaces (inertias $J$ ) are illustrated in Figures 8-11. It is observed that during braking the system attains three distinct dynamic states. From the start of braking at $t=0$ to $t=6.975$, the rotor-stator system is in slip state. This is followed by stick-slip from $t=6.975$ seconds to $t=6.99$ seconds. The third is the stick state during which the vibration amplitude decays to zero. The relative surface angular velocity is plotted in Figure 12.

4.3. Stick-Slip Response. As enumerated, the entire braking can be viewed as consisting of three dynamic states: slip, stick-slip transition, and stick. Figures 13 and 14 illustrate

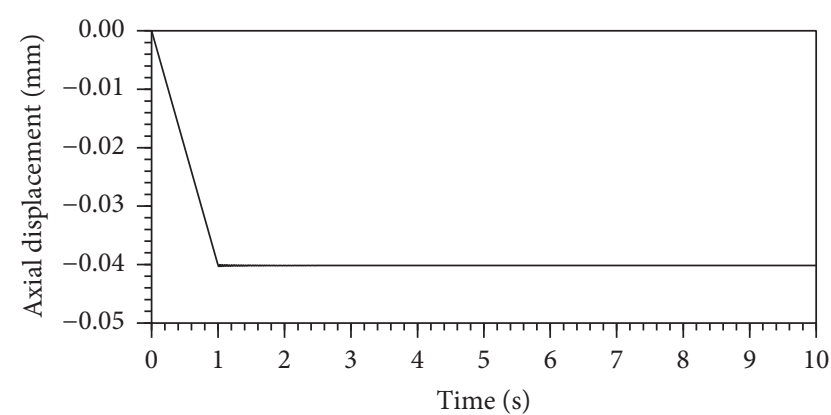

Figure 5: Axial motion.

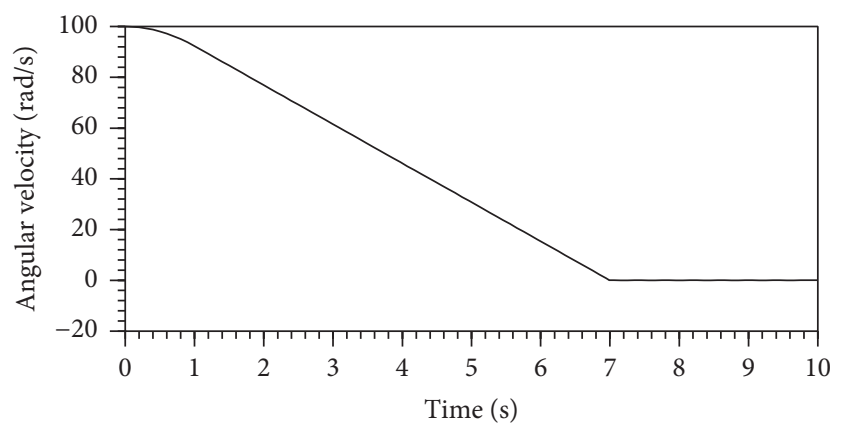

Figure 6: Angular velocity of the rotor.

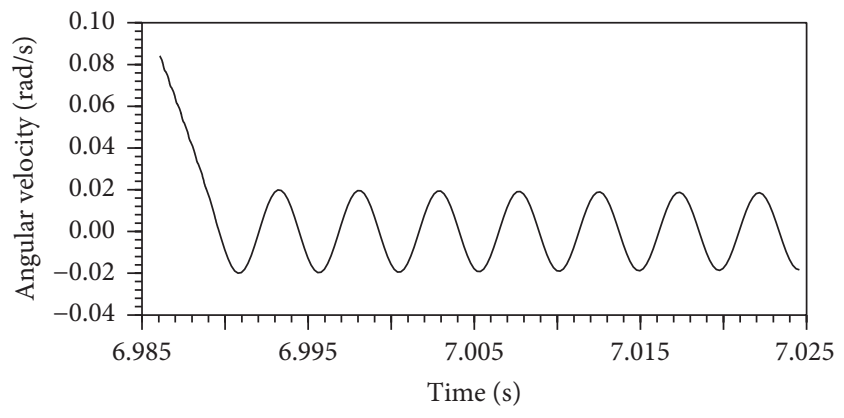

FIgURE 7: Angular velocity of the rotor; close-up view.

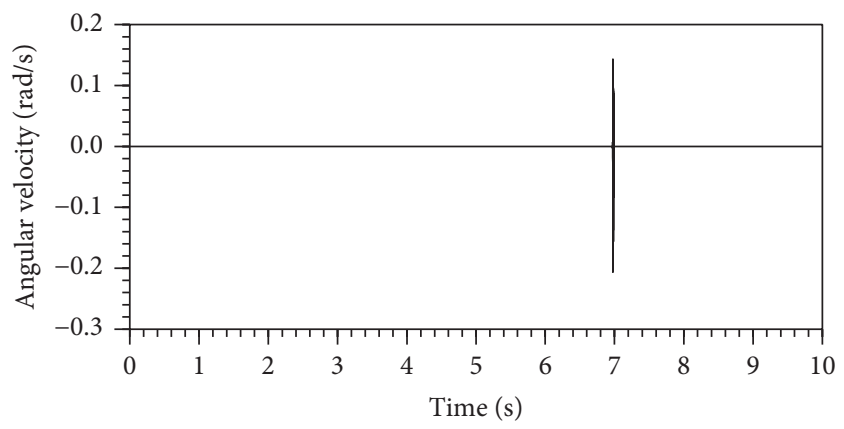

FIGURE 8: Angular velocity of the stator surface.

these three dynamic states. The close-up view of the stickslip transition region in Figure 14 clearly shows that the duration of stick increases within the stick-slip region until a permanent state of sticking is achieved. The stick-slip behavior is presented in greater detail in Figure 15, where the 


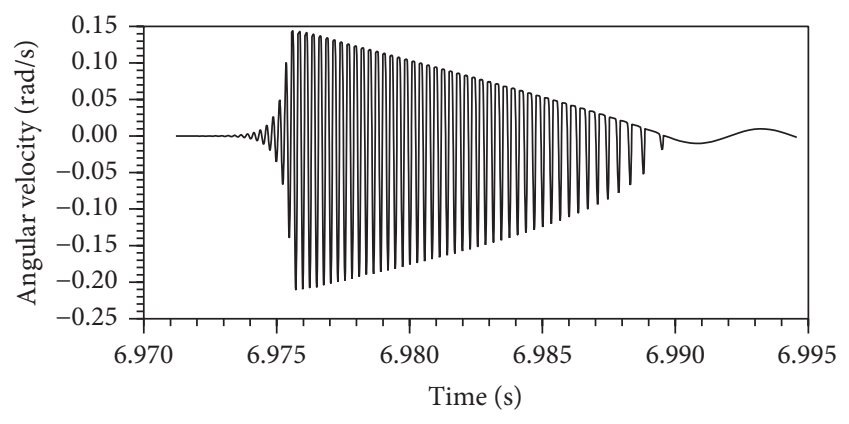

FIGURE 9: Angular velocity of the stator surface; close-up view.

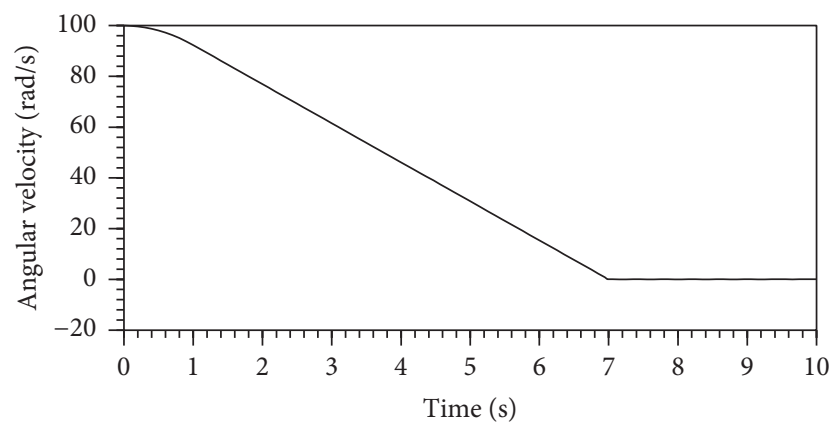

Figure 10: Angular velocity of the rotor surface.

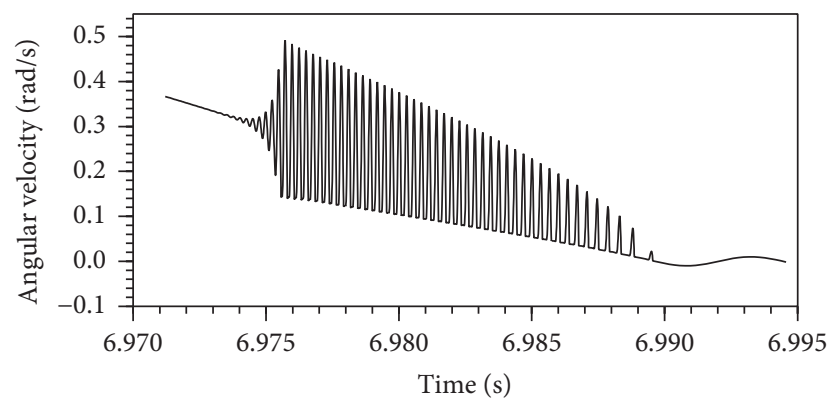

FIGURE 11: Angular velocity of the rotor surface; close-up view.

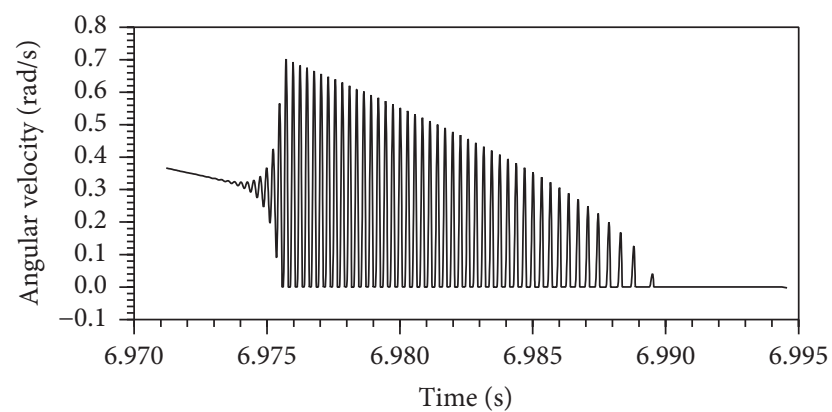

FIGURE 12: Relative angular velocity at the friction interface (rotor surface and stator surface); close-up view.

duration of slip and stick is shown as a function of the number of transitions from slip to stick (index).

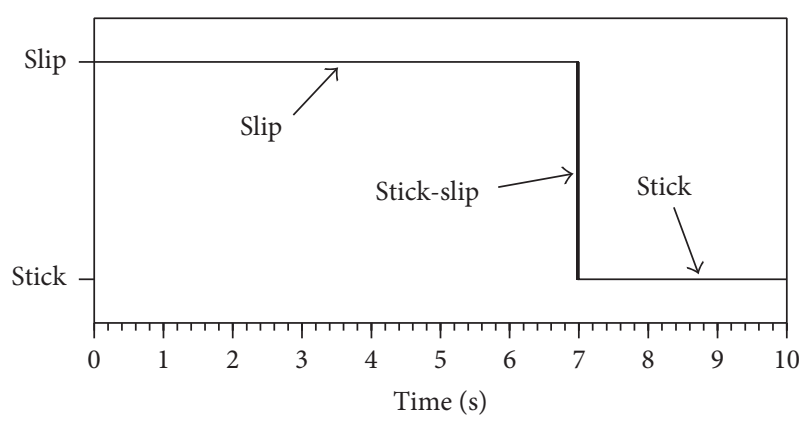

FIgURE 13: Stick-slip transition.

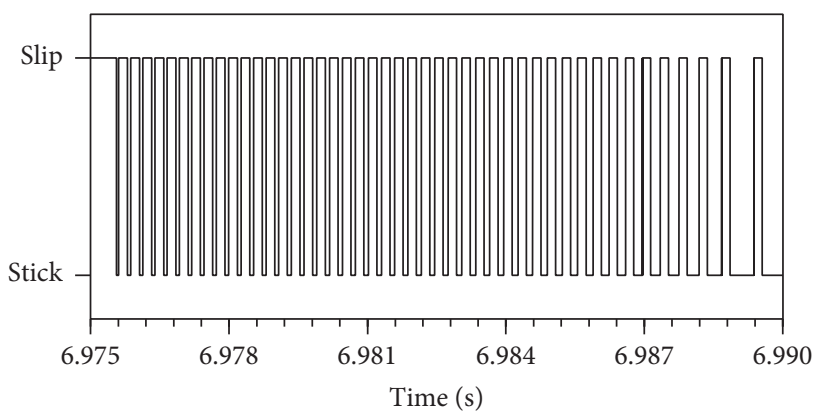

FIGURE 14: Stick-slip transitions; close-up view.

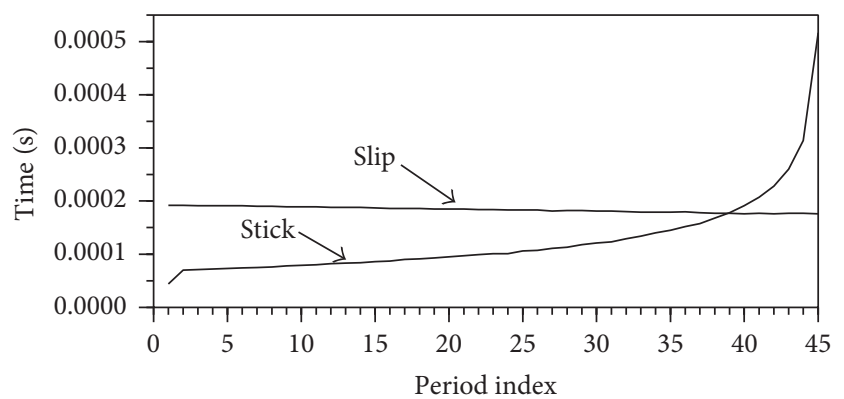

FIGURE 15: Duration of stick and slip period for the transition region.

Examination of the stick-slip transition region has led to the realization that duration of slip is relatively invariant and that stick increases exponentially with time until achieving a steady state of stick (Figure 15).

In the stick-slip transition region a period may be defined as a summation of slip and subsequent stick durations. As mentioned, slip duration is relatively constant at $0.00019 \mathrm{sec}-$ onds. Stick duration starts at 0.00005 seconds and increases to 0.00053 seconds after which the transition region terminates. Considering the periods of stick-slip, the initial period at the onset of the stick-slip response is

$$
T_{i}=0.00005+0.00019=0.00024 \mathrm{~s}
$$

and the final stick-slip period is given by

$$
T_{f}=0.00053+0.00019=0.00072 \mathrm{~s} .
$$




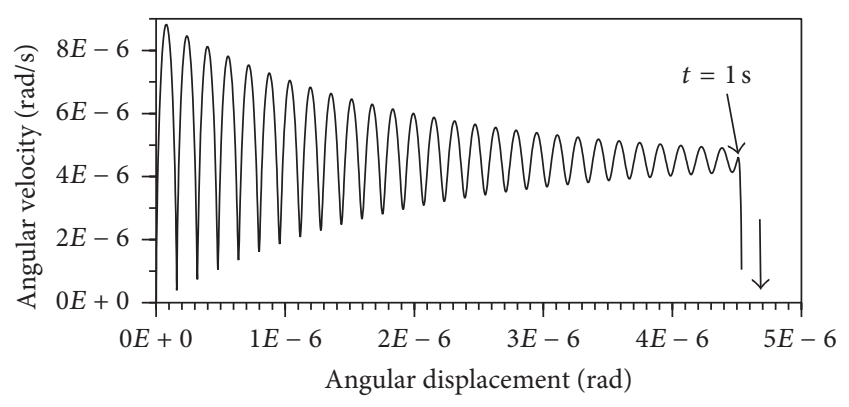

Figure 16: Phase plot $\dot{\theta}-\dot{\phi}_{2}$ versus $\theta-\phi_{2} ; 0$ to $1.008 \mathrm{~s}$.

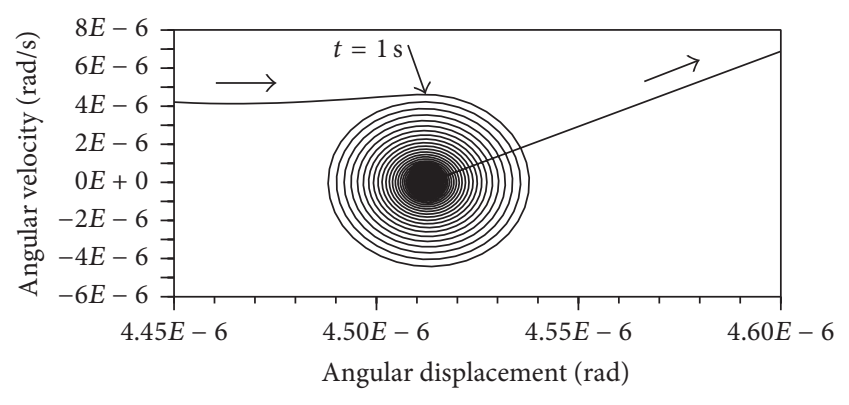

FIGURE 17: Phase plot $\dot{\theta}-\dot{\phi}_{2}$ versus $\theta-\phi_{2} ; 0.9483$ to $6.9467 \mathrm{~s}$.

Considering the highest component natural frequency of the system,

$$
\omega_{n}=\sqrt{\frac{k_{t}}{J}} .
$$

With $k_{t}=7.71 \cdot 10^{6} \mathrm{Nm} / \mathrm{rad}\left(6.822 \cdot 10^{7} \mathrm{lb}\right.$-in $\left./ \mathrm{rad}\right)$ and $J=$ $0.0113 \mathrm{~kg} \mathrm{~m}^{2}$ (0.1 slug-in-ft), we obtain the period

$$
T_{n}=\frac{2 \pi}{\omega_{n}}=0.00024 \mathrm{~s} .
$$

We note that the period of stick-slip at the onset is nearly equal to the period for the highest component natural frequency of the system, $T_{i} \approx T_{n}$, and the final period is nearly equal to three times the period corresponding to the highest component natural frequency of the system, $T_{f} \approx 3 T_{n}$.

4.4. Phase Plot Response. Figures 16-22 depict the phase plots for the lumped parameters representing the rotor and its contact surface. At the start of braking, material elastic deformation (at contact) occurs with decaying oscillatory behavior in rate of deformation (Figure 16). At about $t=1$ second, monotonic increase in material deformation terminates and a stable behavior is observed in the form of a convergent spiral motion, as shown in Figure 17. This stable behavior continues until about $t=6.97$ seconds, where a sudden increase in both material deformation and deformation rate is observed (Figure 18). This turns into an unstable vibration behavior in the form of a divergent spiral (Figure 19) until the onset of the stick-slip behavior (Figure 20). Figure 21 illustrates the stickslip state in which the oscillation amplitude decreases. Finally, at $t=6.9896 \mathrm{~s}$, the stick state prevails and a convergent spiral

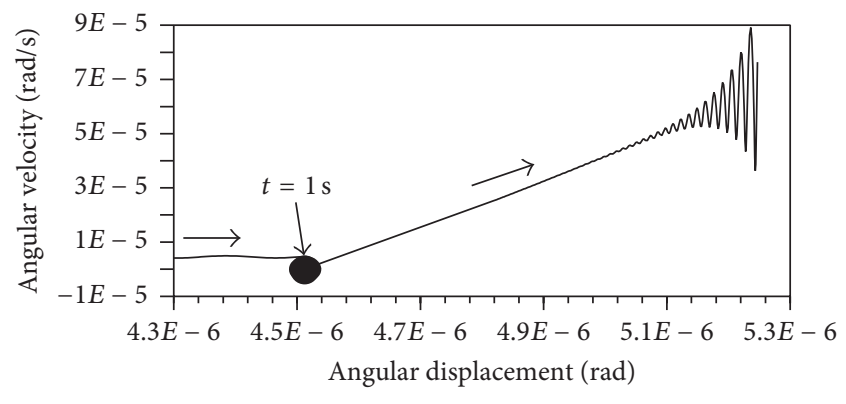

FIGURE 18: Phase plot $\dot{\theta}-\dot{\phi}_{2}$ versus $\theta-\phi_{2} ; 0.9483$ to $6.9714 \mathrm{~s}$.

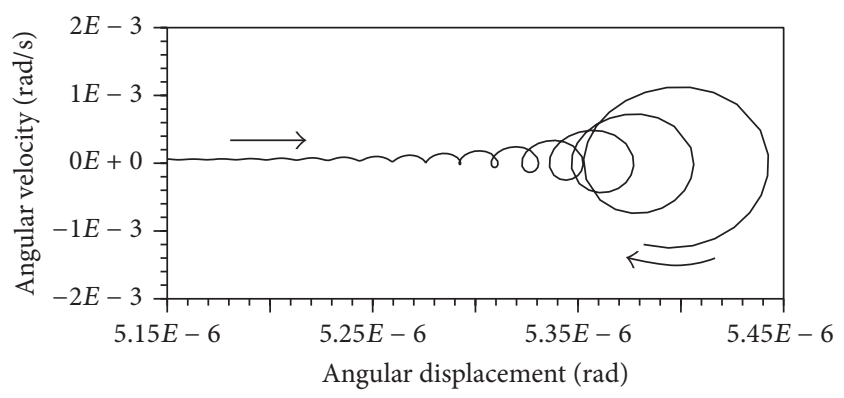

Figure 19: Phase plot $\dot{\theta}-\dot{\phi}_{2}$ versus $\theta-\phi_{2} ; 6.9697$ to $6.9735 \mathrm{~s}$.

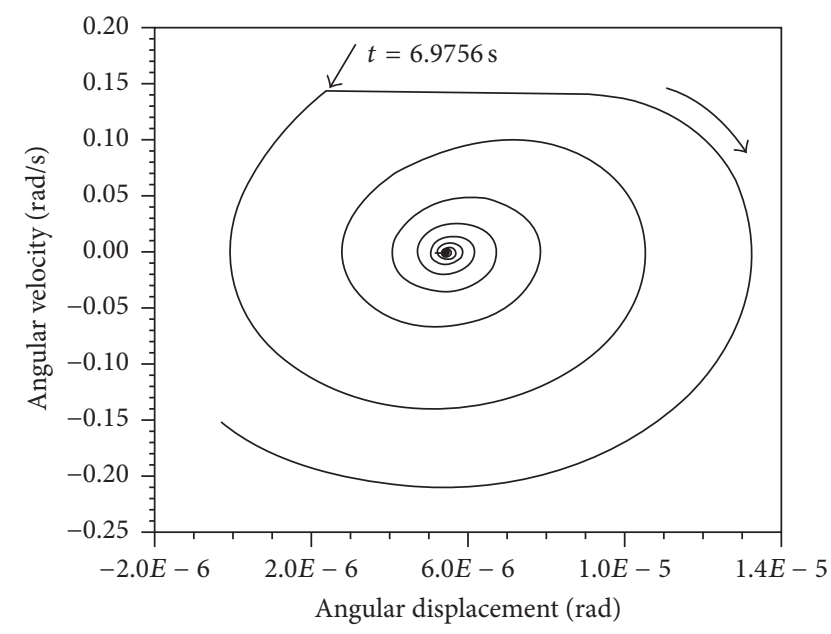

Figure 20: Phase plot $\dot{\theta}-\dot{\phi}_{2}$ versus $\theta-\phi_{2} ; 6.9697$ to $6.9757 \mathrm{~s}$.

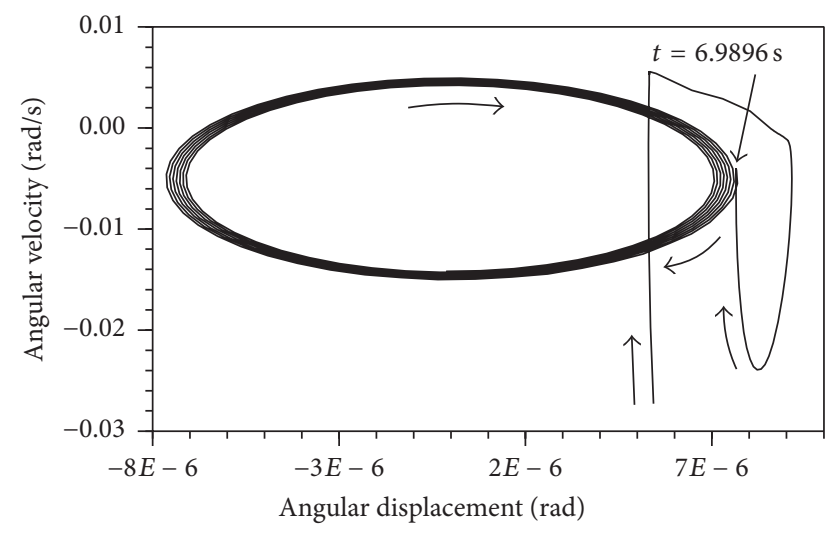

Figure 21: Phase plot $\dot{\theta}-\dot{\phi}_{2}$ versus $\theta-\phi_{2} ; 6.9755$ to 6.9916 s. 


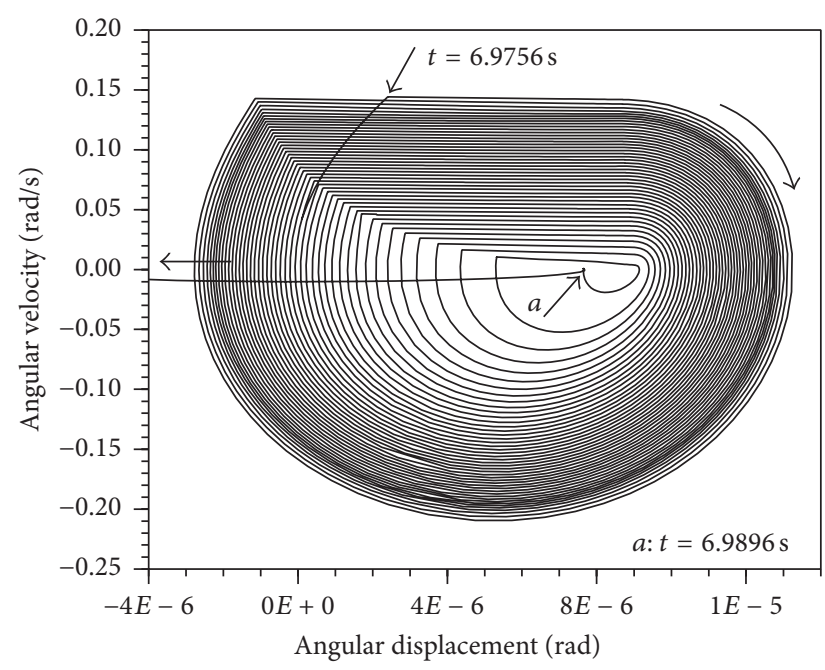

Figure 22: Phase plot $\dot{\theta}-\dot{\phi}_{2}$ versus $\theta-\phi_{2} ; 6.9888$ to $7.0246 \mathrm{~s}$.

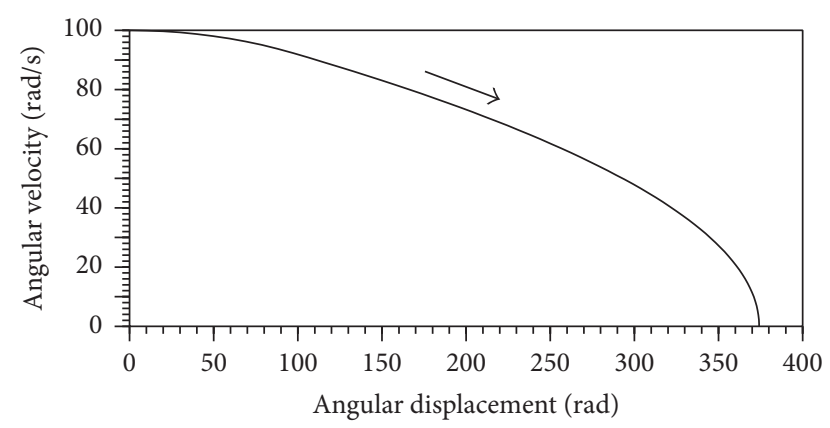

FIgURE 23: Phase plot $\dot{\phi}_{2}-\dot{\phi}_{1}$ versus $\phi_{2}-\phi_{1} ; 0$ to $10 \mathrm{~s}$.

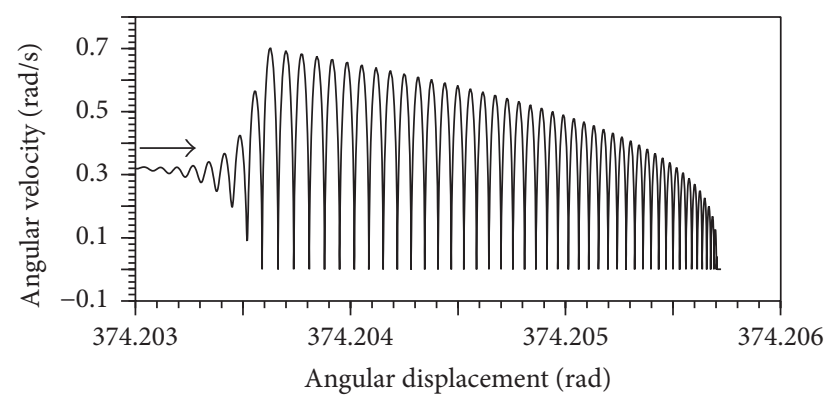

FIgURe 24: Phase plot $\dot{\phi}_{2}-\dot{\phi}_{1}$ versus $\phi_{2}-\phi_{1} ; 6.9728$ to $10 \mathrm{~s}$.

behavior is observed, as depicted in Figure 22. Figures 23 and 24 present the phase plots for the relative surface velocity.

4.5. Critical Parameters for Stick-Slip. The investigation of stick-slip behavior of the two-disk friction system results in establishing pairs of material damping and friction coefficient decay rate values for which the occurrence of stick-slip can be predicted.

Here a parametric study for different $\alpha$ and $c_{t}$ values is presented. The number of stick-slip transitions is counted and is used to determine the critical pairs of $\alpha$ and $c_{t}$.

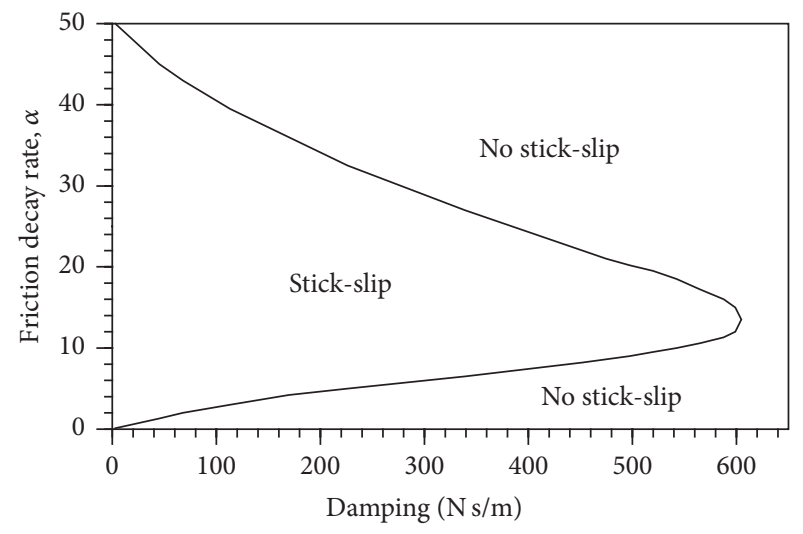

FIGURE 25: Critical decay rate, $\alpha$, and damping values, $c_{t}$, for the twodisk brake system.

The critical values are defined to be those for which stickslip transition region starts to disappear. Figure 25 depicts the resulting curve corresponding to critical $\alpha-c_{t}$ pairs. As illustrated, the domain is divided into two regions. The space enclosed within the curve and the $\alpha$-axis provide the $\alpha-c_{t}$ pairs for which stick-slip behavior will take place. For the region outside the critical $\alpha-c_{t}$ curve stick-slip behavior does not exist.

The main utility of the result in Figure 25 lies in illustrating the connection between material and interface properties and the dynamic behavior of the two-disk system. If such properties can be traced back to the parameters used in fabrication of the friction material, then a figure such as Figure 25 can serve as a valuable design aid in deciding material composition and fabrication methods to be used so as to achieve a desired dynamic behavior of the resulting system.

\section{Conclusion}

A lumped parameter model for the prediction of vibration response of two-disk brake system has been developed. The model is capable of predicting brake response, including the stick-slip transition phase. Using this capability an investigation of friction-induced vibration and stick-slip phenomenon has been performed.

Examination of stick-slip transition region revealed that duration of slip is relatively invariant and that duration of stick increases nonlinearly with time until achieving a steady state of stick.

Critical values of the material damping and friction coefficient decay rate are found which divide the domain of the two parameters into two regions: one in which stick-slip behavior occurs and the other in which stick-slip will not occur.

The result of the investigation may be summarized as follows:

(1) Duration of slip in the stick-slip transition region is relatively invariant.

(2) Duration of stick increases almost exponentially with time until a final stick state is achieved. 
(3) The period of stick-slip at the beginning of the stickslip region is approximately equal to the period corresponding to the highest component natural frequency of the system.

(4) The final period is approximately equal to three times the period corresponding to the highest component natural frequency of the system.

(5) A critical curve (Figure 25), defined by set of material damping and friction coefficient decay rate values, is found that defines the region where stick-slip occurs. The resulting curve shows that, for structural damping in the range $0-600 \mathrm{~N} \mathrm{~s} / \mathrm{m}$, there are two limit values for friction-velocity decay rate within which stickslip would occur. The range of friction-velocity decay rate corresponding to stick-slip response increases for lower structural damping within the brake.

\section{Nomenclature}

$t$ : Time

$t_{0}$ : Application time for the actuating axial force

$F_{0}$ : Actuating normal force

$F(t)$ : Axial actuating force as a function of time

$F_{n}$ : Normal surface interface force

$m$ : Mass of the rotor

$k_{e}$ : Equivalent axial stiffness of a disk pair

$c_{a}$ : Axial damping of a disk pair

$z$ : Axial displacement of the rotor

I: $\quad$ Inertia of the rotor

$J$ : Equivalent inertia lumped at the friction surface contributed by a disk

$k_{t}$ : Equivalent torsional contact stiffness contributed by a disk

$c_{t}$ : Equivalent torsional contact damping coefficient contributed by a disk

$D$ : Outer diameter of each friction disk

$d$ : Inner diameter of each friction disk

$r$ : Effective radius of tangential force

$\theta$ : Angular rotation of the rotor

$\phi_{1}$ : Angular rotation of the friction surface on the stator

$\phi_{2}$ : Angular rotation of the friction surface on the rotor

$\omega_{r}: \quad$ Relative angular velocity

$\omega_{n}$ : Highest component natural frequency for the rotational system

$F_{i}$ : Internal force generated by spring and damper

$T_{i}$ : Initial stick-slip period

$T_{f}$ : Final stick-slip period

$T_{n}$ : Period corresponding to $\omega_{n}$

$\mu_{H}$ : Friction coefficient function

$\mu_{0}$ : Breakaway friction coefficient

$\mu_{s}$ : Friction coefficient for low relative velocities

$\mu_{d}$ : Friction coefficient for high relative velocities $\alpha$ : Friction coefficient decay rate with increase in relative velocity

$\varepsilon$ : Relative angular velocity tolerance

$\delta$ : Dirac delta function.

\section{Competing Interests}

The authors declare that they have no competing interests.

\section{Acknowledgments}

The authors would like to acknowledge the financial support for this project provided by the Center for Advanced Friction Studies at Southern Illinois University Carbondale.

\section{References}

[1] R. A. Ibrahim, "Friction-induced vibration, chatter, squeal, and chaos: part I-mechanics of friction," in Friction-Induced Vibration, Chatter, Squeal, and Chaos, vol. 49, pp. 107-121, Transactions of the ASME, 1992.

[2] R. A. Ibrahim, "Friction-induced vibration, chatter, squeal, and chaos-part II: dynamics and modeling," Applied Mechanics Reviews, vol. 47, no. 7, pp. 227-253, 1994.

[3] B. Armstrong-Hélouvry, "Friction: experimental determination, modeling and compensation," in Proceedings of the International Conference on Robotics and Automation (ICRA '88), pp. 1422-1427, IEEE, Philadelphia, Pa, USA, 1988.

[4] B. Armstrong-Hélouvry, "Stick-slip arising from Stribeck friction," in Proceedings of the IEEE International Conference on Robotics and Automation, pp. 1377-1382, IEEE, Cincinnati, Ohio, USA, May 1990.

[5] B. Armstrong-Hélouvry, "A perturbation analysis of stick-slip," in Friction-Induced Vibration, Chatter, Squeal, and Chaos, vol. 49, pp. 41-48, Transactions of the ASME, 1992.

[6] B. Armstrong-Hélouvry, P. Dupont, and C. C. De Wit, "A survey of models, analysis tools and compensation methods for the control of machines with friction," Automatica, vol. 30, no. 7, pp. 1083-1138, 1994.

[7] D. A. Crolla and A. M. Lang, "Brake noise and vibration-the state of the art," Vehicle Tribology, vol. 18, pp. 165-174, 1990.

[8] D. Tabor, "Friction-the present state of our understanding," Journal of Lubrication Technology, vol. 103, no. 2, pp. 169-179, 1981.

[9] J. T. Oden and J. A. C. Martins, "Models and computational methods for dynamic friction phenomena," Computer Methods in Applied Mechanics and Engineering, vol. 52, no. 1-3, pp. 527634, 1985.

[10] J. A. Martins, J. T. Oden, and F. M. Simões, "A study of static and kinetic friction," International Journal of Engineering Science, vol. 28, no. 1, pp. 29-92, 1990.

[11] U. Galvanetto and S. R. Bishop, "Stick-slip vibrations of a two degree-of-freedom geophysical fault model," International Journal of Mechanical Sciences, vol. 36, no. 8, pp. 683-698, 1994.

[12] K. Popp, "Some model problems showing stick-slip motion and chaos," in Friction-Induced Vibration, Chatter, Squeal, and Chaos, vol. 49, pp. 1-12, Transactions of the ASME, 1992.

[13] C. Gao, "Stick-slip motion in boundary lubrication," Tribology Transactions, vol. 38, no. 2, pp. 473-477, 1995. 
[14] W. W. Tworzydlo, E. B. Becker, and J. T. Oden, "Numerical modeling of friction-induced vibrations and dynamic instabilities," in Friction-Induced Vibration, Chatter, Squeal, and Chaos, vol. 49, pp. 13-32, Transactions of the ASME, 1992.

[15] A. Soom and C. Kim, "Rougness induced dynamic loading at dry and boundary-lubricated sliding contacts," ASME Journal of Lubrication Technology, vol. 105, no. 4, pp. 514-517, 1983.

[16] A. Soom and C. Kim, "Interactions between dynamic normal and frictional forces during unlubricated sliding," ASME Journal of Lubrication Technology, vol. 105, no. 2, pp. 221-229, 1983.

[17] A. H. Dweib and A. F. D'Souza, "Self-excited vibrations induced by dry friction, part 1: experimental study," Journal of Sound and Vibration, vol. 137, no. 2, pp. 163-175, 1990.

[18] P. E. Dupont and D. Bapna, "Perturbation stability of frictional sliding with varying normal force," Journal of Vibration and Acoustics, vol. 118, no. 3, pp. 491-497, 1996.

[19] J. A. C. Martins, L. O. Faria, and J. Guimarães, "Dynamic surface solutions in linear elasticity with frictional boundary conditions," in Friction-Induced Vibration, Chatter, Squeal, and Chaos, vol. 49, pp. 33-39, American Society of Mechanical Engineers, 1992.

[20] C. Gao, D. Kuhlmann-Wilsdorf, and D. D. Makel, "The dynamic analysis of stick-slip motion," Wear, vol. 173, no. 1-2, pp. 1-12, 1994.

[21] H.-I. You and J.-H. Hsia, "Influence of friction-speed relation on the occurrence of stick-slip motion," Journal of Tribology, vol. 117, no. 3, pp. 450-455, 1995.

[22] Y. Yuan, "A study of the effects of negative friction-speed slope on brake squeal," in Proceedings of the ASME Design Engineering Technical Conferences, vol. 84, pp. 1153-1162, 1995.

[23] R. J. Black, "Self-excited multi-model vibrations of aircraft brakes with nonlinear negative damping," in Proceedings of the ASME Design Engineering Technical Conferences, vol. 84, no. 1, pp. 1241-1245, 1995.

[24] M. T. Bengisu and A. Akay, "Stability of friction-induced vibrations in multi-degree-of-freedom systems," in Friction-Induced Vibration, Chatter, Squeal, and Chaos, vol. 49, pp. 57-64, American Society of Mechanical Engineers, 1992.

[25] R. Avilés, G. Hennequet, E. Amezua, and J. Vallejo, "Low frequency vibrations in disc brakes at high car speed. Part II: mathematical model and simulation," International Journal of Vehicle Design, vol. 16, no. 6, pp. 556-569, 1995.

[26] L. C. Bo and D. Pavelescu, "The friction-speed relation and its influence on the critical velocity of stick-slip motion," Wear, vol. 82, no. 3, pp. 277-289, 1982.

[27] A. F. D'Souza and A. H. Dweib, "Self-excited vibrations induced by dry friction-part 2: stability and limit-cycle analysis," Journal of Sound and Vibration, vol. 137, no. 2, pp. 177-190, 1990.

[28] J. L. Swayze and A. Akay, "Effects of system dynamics on friction-induced oscillations," Journal of Sound and Vibration, vol. 173, no. 5, pp. 599-609, 1994.

[29] H. A. Sherif and S. S. Kossa, "Relationship between normal and tangential contact stiffness of nominally flat surfaces," Wear, vol. 151, no. 1, pp. 49-62, 1991.

[30] H. A. Sherif, "Effect of contact stiffness on the establishment of self-excited vibrations," Wear, vol. 141, no. 2, pp. 227-234, 1991.

[31] C. Gao, D. Kuhlmann-Wilsdorf, and D. D. Makel, "Fundamentals of stick-slip," Wear, vol. 162-164, pp. 1139-1149, 1993.

[32] S. Jang and J. Tichy, "Rheological models for stick-slip behavior," Tech. Rep. 96-TRIB-52, 1996.
[33] A. Polycarpou and A. Soom, "Transitions between sticking and slipping at lubricated line contacts," in Friction-Induced Vibration, Chatter, Squeal, and Chaos, vol. 49 of Transactions of the ASME, pp. 139-148, American Society of Mechanical Engineers, 1992.

[34] G. G. Adams, "Self-excited oscillations in sliding with a constant friction coefficient," in Proceedings of the ASME Design Engineering Technical Conferences, vol. 84, no. 1, pp. 1171-1177, 1995.

[35] D. A. Haessig Jr. and B. Friedland, "On the modeling and simulation of friction," ASME Journal of Dynamic Systems, Measurement and Control, vol. 113, no. 3, pp. 354-362, 1991.

[36] J. E. Shigley and C. R. Mischke, Mechanical Engineering Design, McGraw-Hill, New York, NY, USA, 5th edition, 1989. 


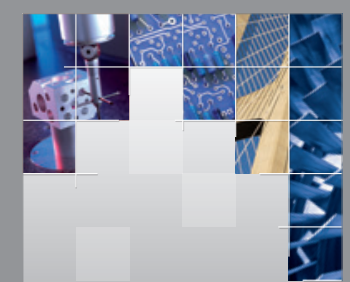

\section{Enfincering}
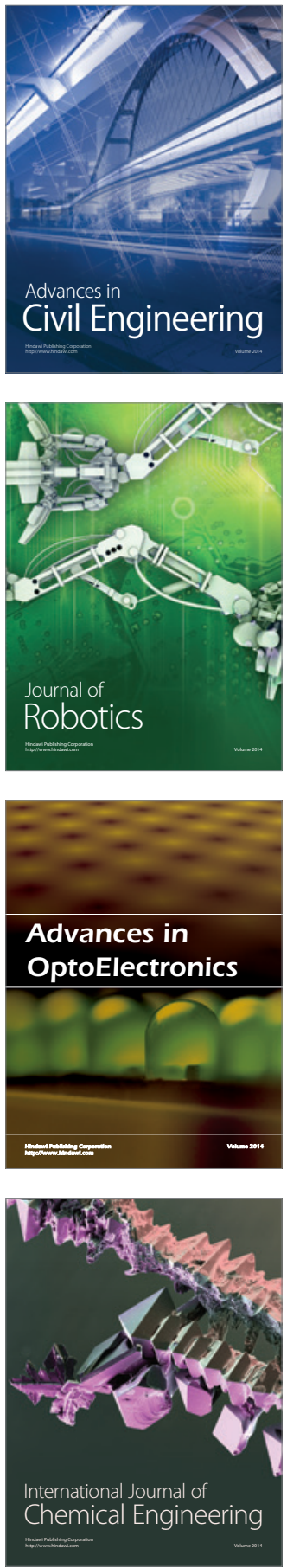

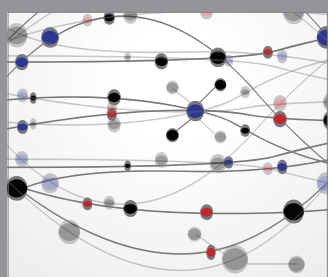

The Scientific World Journal

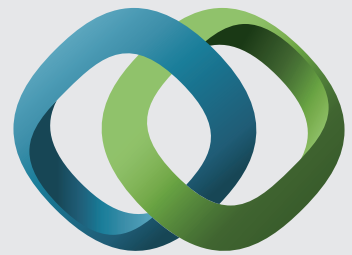

\section{Hindawi}

Submit your manuscripts at

http://www.hindawi.com
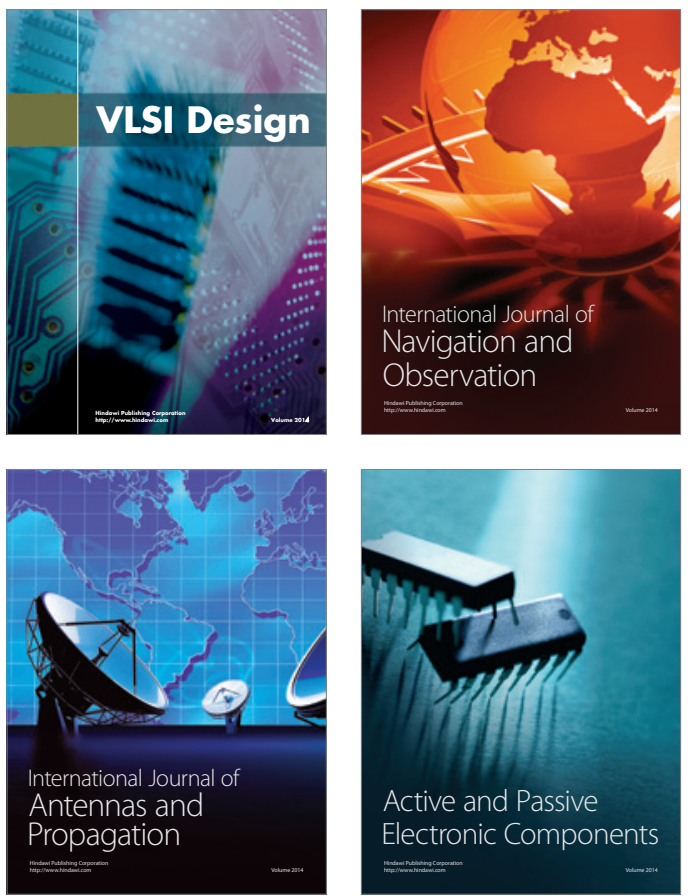
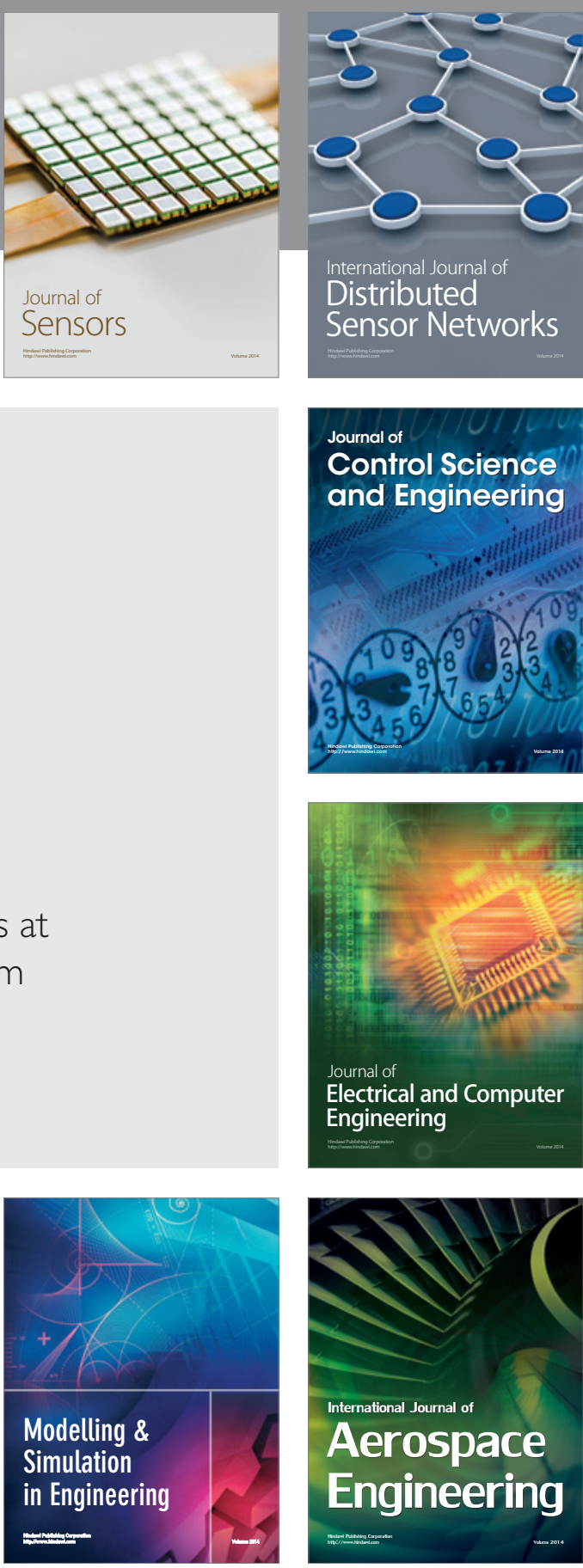

International Journal of

Distributed

Sensor Networks

Journal of

Control Science

and Engineering
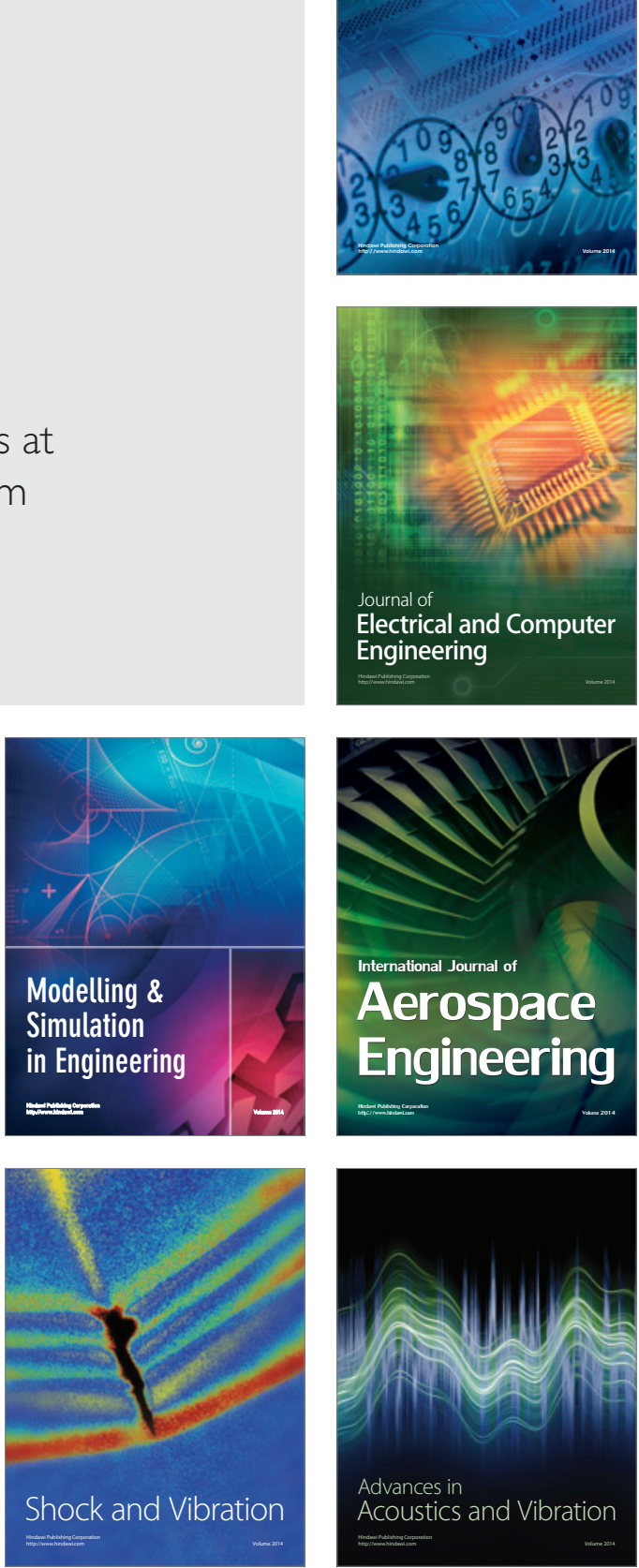